\title{
EVALUATION OF RATIONAL QUANTITY OF PROFILE MOMENT-TRANSFERRING JOINTS SIDES
}

\author{
Mikhail Sergeyevich Razumov, Aleksey Olegovich Gladyshkin, Aleksey Ivanovich Pykhtin
}

Preliminary notes

The article contains description of the way for calculation of torque and defining a rational quantity of profile joints sides, as well as a scheme of a system for automated calculation of many-sided moment-transferring joints.

Keywords: durability; profile joints; torque

Procjena racionalne količine stranica profilnih spojeva za prijenos okretnog momenta

Prethodno priopćenje Članak sadrži opis načina za izračunavanje okretnog momenta i definiranja racionalne količine stranica profilnih spjeva, kao i shemu sustava za automatizirano izračunavanje višestraničnih spojeva za prijenos okretnog momenta.

Ključne riječi: okretni moment; postojanost; profilni spojevi

\section{Introduction}

Optimisation of designing process of any mechanism is a complex task, due to restrictions of various factors, such as dimensions, material etc.

Profile junctions have a number of advantages [1] in comparison to splined and key junctions.

Profile junctions have various forms in section. The simplest to produce are junctions having the crosssectional shape of a regular polygon. They are widely used in the mining industry. Augers with shafts of a side form for transfer of torque momentum are widely used for drilling of engineering-geological, seismic-prospecting and technical drills. Such junctions can be made on various types of equipment [2, 3, 4]. Therefore the designer should define a rational number of sides for creation of optimal dimensions and durability values.

For faceted surfaces with an increase in the number of $n$-sided figure sides, the underlying section increases the ability to transmit torque, which in turn gives the greatest strength. However, increasing the number of edges, underlying figure section will tend to circumference, which in turn can cause wrinkling faces. Accordingly, there is an urgent task for the selection of a rational number of faces on the basis of the following parameters: the material used, the required length of the work surface, which depends on the constructive use (mobile or fixed connection). Required to find a number of facets, where the maximum torque will be, and a chance faces collapse will be excluded. To find such dependence it is necessary to calculate the strength and reliance on collapse for junctions.

\section{Method}

Expression [5] is a formula for calculating the strength. In calculating the strength the formula for calculating the maximum shear stress was used:

$$
\tau_{\max }=\frac{T_{\max } \cdot y_{\max }}{I_{\rho n}}
$$

where $T_{\max }-$ maximum torque, transferred by a junction; $I_{\rho n}$ - polar moment of inertia; $y_{\max }$ - maximum distance from the gravity center to the extreme point of a profile (a half of diameter of a circumscribed circle).

$I_{\rho n}=n \cdot \frac{R^{4} \cdot \sin \frac{360^{\circ}}{n}}{12} \cdot\left(\cos \frac{360^{\circ}}{n}+2\right)$,

where $n$ - quantity of sides; $R$ - radius of a circumscribed circle.

For calculation of side surfaces crumpling it is necessary to define a formula of maximum torque providing the set form of cross section. We use formulas of materials resistance in order to define this formula:

$\sigma_{\max }=\frac{F}{A}$

where $\sigma_{\max }$ - maximum normal stress; $F$ - force which causes a shift; $A$ - crumpling area.

$A=l \cdot h$,

where $l$-length of profile part; $h$ - difference between radius of the inscribed and circumscribed circle in a profile figure.

Torque $T$ is a pair of forces; these forces cause crumpling of sides. They can be defined as follows:

$T=F \cdot l_{1} \rightarrow F=\frac{T}{l_{1}}$,

where $l_{1}-$ arm of force effect. 
$h=R-r$,

$r=R \cdot \cos \frac{\pi}{n}$

When putting (4), (5), (6) and (7) into the formula (3), we get:

$$
\sigma_{\text {max }}=\frac{T}{l_{1} \cdot l \cdot\left(R-R \cdot \cos \frac{\pi}{n}\right)} .
$$
(8):

The value of torque can be defined from the formula

$$
\begin{aligned}
& T=\sigma_{\max } \cdot R \cdot l \cdot\left(R-R \cdot \cos \frac{\pi}{n}\right)= \\
& =\sigma_{\max } \cdot R^{2} \cdot l \cdot\left(1-\cos \frac{\pi}{n}\right) .
\end{aligned}
$$
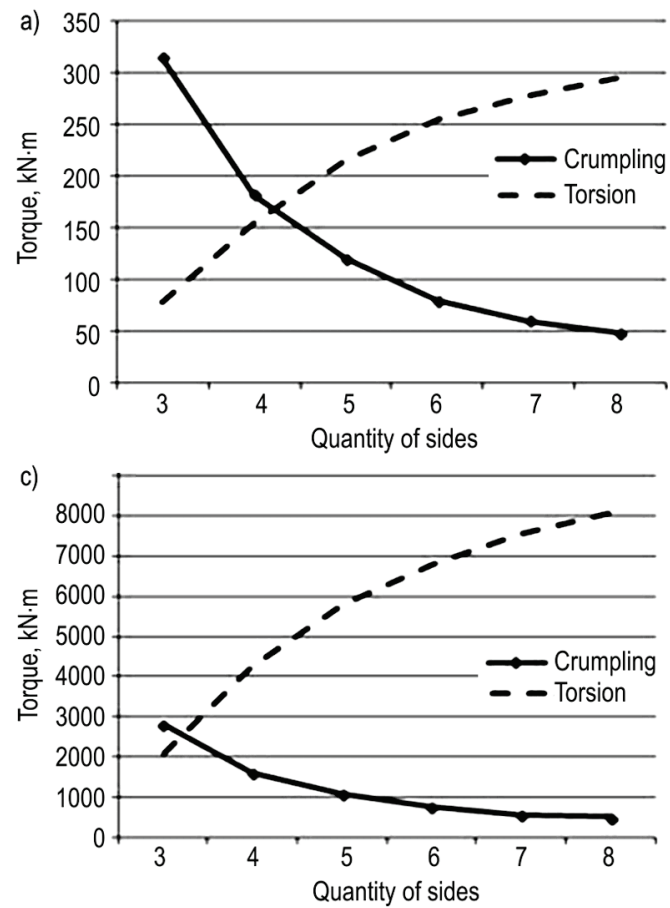

Figure 1 Diagrams for calculation of junctions optimal parameters: a) $D=25 \mathrm{~mm}, \mathrm{~b}) D=50 \mathrm{~mm}$, c) $D=75 \mathrm{~mm}$, d) $D=100 \mathrm{~mm}$

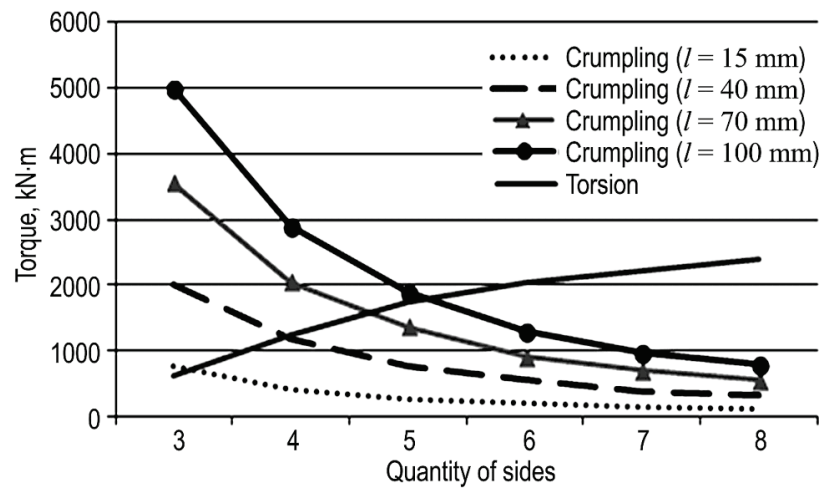

Figure 2 Diagrams for calculation of the optimal parameters of profile junctions when $l=15 \mathrm{~mm}, l=40 \mathrm{~mm}, l=70 \mathrm{~mm}, l=100 \mathrm{~mm}$

\section{Results and discussion}

Using formulas (1), (2) and (9) we obtain dependence, at the intersection of which we obtain a rational value for the number of faces in which the maximum strength of the shaft does not lead to the collapse of surfaces. Making a table of values shown by the experimental sample, we construct the graphs of finding rational values of the number of faces for a specific length of the profile of the part. For example, for the circumscribed circle diameter $D=25,50,75$ and 100 $\mathrm{mm}$, respectively, when the length of the profile surface $l$ $=25 \mathrm{~mm}$, normal stress $R_{\mathrm{m}}=160 \mathrm{MPa}$, the graphics will have the following form (see Fig. 1).

The diagrams show that the rational quantity of sides increases while diameter of the shaft is decreasing.

At a constant circumscribed circle $D=50 \mathrm{~mm}$, various lengths of profile surface $l=15,40,70$ and 100 $\mathrm{mm}$, normal stress $\sigma_{\mathrm{v}}=160 \mathrm{MPs}$, diagrams will be as follows (Fig. 2).
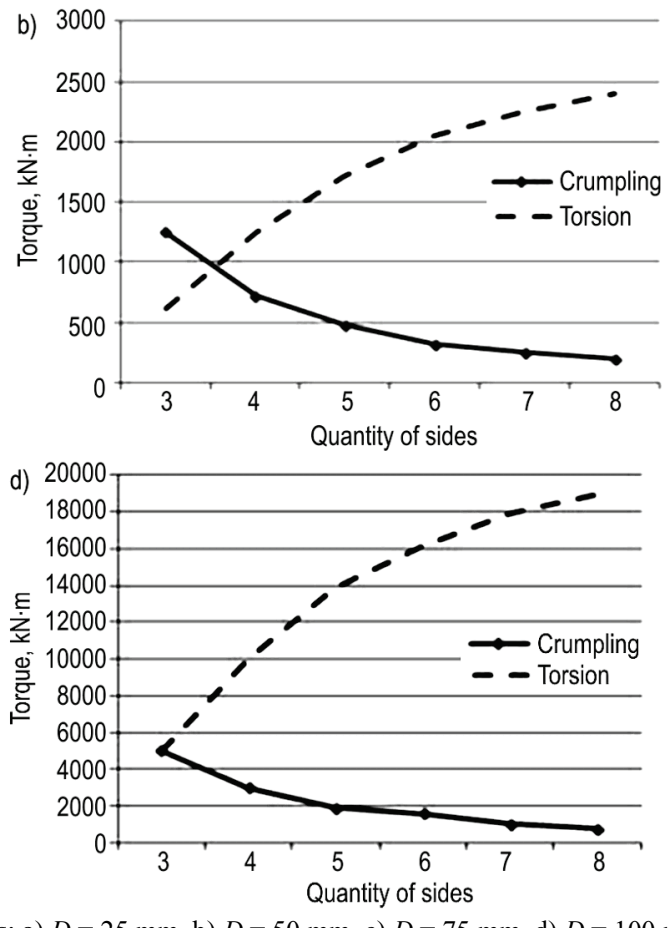

Data analysis of the graphs shows that increasing the length of the profile surface leads to increase of rational number of facets.

Based on the above studies, using the formulas obtained, it was possible to design an automated program for calculation of rational numbers of faces of the profile junctions on the basis of information about the initial dimensions and material properties of the elements of the junction.

The developed program has an interactive interface. In the first dialog box (see Fig. 3) operator needs to enter diameter of the circumference of the shaft profile, estimated number of facets of the junction yield strength of the material, length of the profile surface and a coefficient that takes into account the effect of shear stresses. 


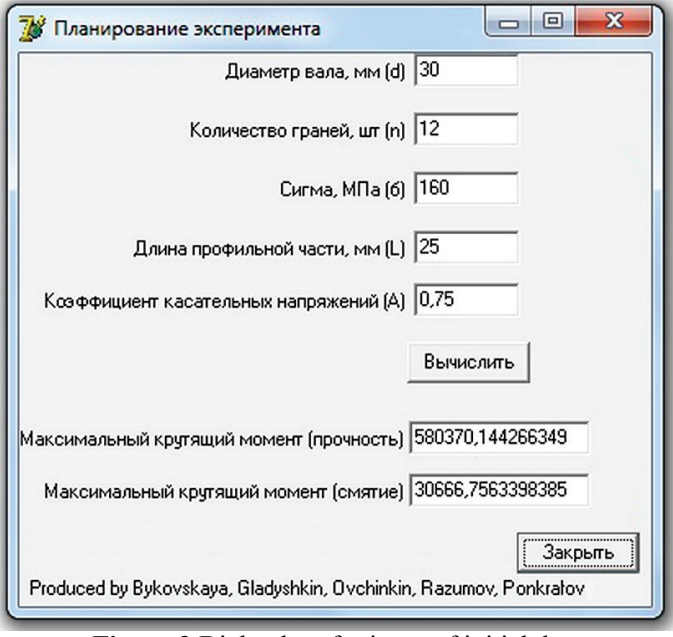

Figure 3 Dialog box for input of initial data

The program calculates and displays interactively corresponding values of maximum torque strength and shear stress for the design element of the junction. In the second dialog box in the form of graphic information display graphs superimposed torques taking into account depending on the strength and buckling is displayed (see Fig. 4).

The point of intersection of these curves shows a rational number of faces for the chosen parameters. When a user returns to the first dialog it is possible to change the number of faces on the recommended schedule. This will restate the corresponding values.

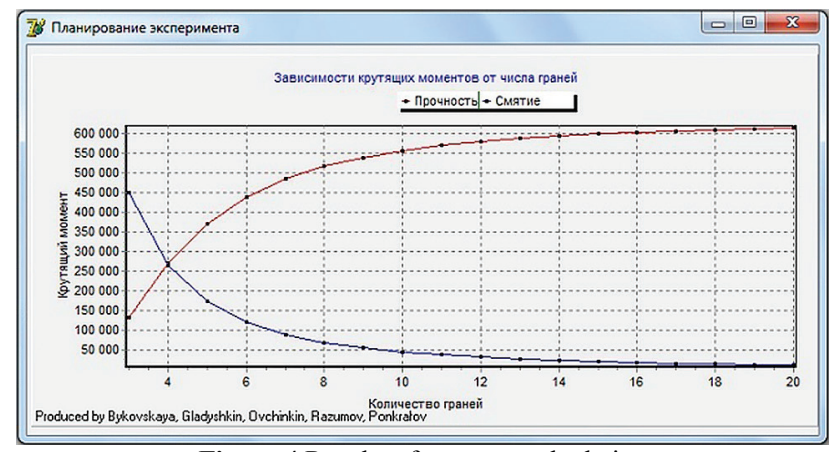

Figure 4 Results of program calculation

The cross points of these curves show a rational quantity of sides for the selected parameter. A number of sides can be modified for recommended one, according to diagrams, when returning back to the first dialogue box. Thus corresponding values will be recalculated.

\section{Acknowledgements}

The work was executed with financial support of the grant of the president of the Russian Federation for the state support of young Russian scientists - candidates of sciences MK-2653.2014.8.

\section{References}

[1] Timchenko, A. I. Technology of production of keyless joints details profiles. M. Vniitumr, 1988. $160 \mathrm{p}$.

[2] Barbotko, A. I.; Ponkratov, P. A.; Razumov, M. S Technology of processing of profile shaft by cup cutters. // XVII International correspondence scientific and practical conference "Engineering sciences - from the theory to practice". Novosibirsk, ed. SibAK. p. 1, (2013), pp. 75-79.

[3] Razumov, M. S. Thesis of candidate of technical sciences. // Increase of forming productivity of many-sided external surfaces by means of planetary mechanism. - Kursk: 05.02.07, 2011.

[4] Emelyanov, S. G. Automation of technological preparation of profile shaft production. / Emelyanov, S. G.; Gladyshkin, A. O.; Razumov, M. S.; Jatsun, S. F. //News of Southwest state university. No. 1(40), p. 1(2012), pp. 164-168.

[5] Kassikhin, V. N.; Razumov, M. S.; Gladyshkin, A. O.; Bykovskaya, N. E. Automation of durability calculation for shaft torsion. // News of Southwest state university, Equipment and technologies, SWSU. No. 2, p. 1(2012), pp. 179-181.

\section{Authors' addresses}

Razumov Mikhail Sergeyevich, candidate of science, senior teacher of the city, road building and the building mechanics department SWSU

South-West State University,

st. 50 let Oktyabrya, 94

305040 Kursk, Russia

E-mail: mika_1984_@mail.ru

Gladyshkin Aleksey Olegovich, candidate of science, senior lecturer of the city, road building and the building mechanics department SWSU

South-West State University,

st. 50 let Oktyabrya, 94

305040 Kursk, Russia

E-mail: gladfilat@yandex.ru

Pykhtin Aleksey Ivanovich, candidate of science, executive secretary PK SWSU

South-West State University,

st. 50 let Oktyabrya, 94

305040 Kursk, Russia

E-mail:kstu.ee@gmail.com 